\title{
Stock Returns, Illiquidity and Feedback Trading
}

\begin{tabular}{|r|l|}
\hline Journal: & Review of Accounting and Finance \\
\hline Manuscript ID & RAF-02-2017-0024.R4 \\
\hline Manuscript Type: & Research Paper \\
\hline Keywords: & stock returns, liquidity, feedback \\
\hline & \\
\end{tabular}

SCHOLARONE
Manuscripts

Publisher policy allows this work to be made available in this repository. Published in Review of Accounting and Finance by Emerald. The original publication is available at https://doi.org/10.1108/RAF-02-2017-0024. This article is deposited under the Creative Commons Attribution Non-commercial International Licence 4.0 (CC BY-NC 4.0). Any reuse is allowed in accordance with the terms outlined by the licence (https://creativecommons.org/licenses/by-nc/4.0/). To reuse the AAM for commercial purposes, permission should be sought by contacting permissions@emeraldinsight.com. 


\title{
Stock Returns, Illiquidity and Feedback Trading
}

\author{
February 2017 \\ Revised June 2017 \\ Second Revision December 2017 \\ This Version July 2018
}

\begin{abstract}
We examine the relation between illiquidity, feedback trading and stock returns for several European markets, using panel regression methods, during the financial and the sovereign debt crises. Our interest here is twofold. First, we seek to compare the results obtained here, under crisis conditions, with those in the existing literature. Second, and of greater importance, we wish to examine the interaction between liquidity and feedback trading and their effect on stock returns. The key results suggest that in common with the literature, illiquidity has a negative impact upon contemporaneous stock returns, while supportive evidence of positive feedback trading is reported. However, in contrast to the existing literature, lagged illiquidity is not a priced risk, while negative shocks do not lead to greater feedback trading behaviour. Regarding the interaction between illiquidity and feedback trading, our results support the view that greater illiquidity is associated with stronger positive feedback. This suggests that when price changes are more observable, due to low liquidity, then feedback trading increases. Therefore, during the crisis periods that afflicted European markets, the prevalent lower levels of liquidity led to an increase in feedback trading. Thus, negative liquidity shocks that led to a fall in stock prices were exacerbated by feedback trading.
\end{abstract}

Keywords: Stock Returns, Liquidity, Feedback JEL: C22, G12 


\section{Introduction.}

This paper examines the impact of illiquidity and the interaction between illiquidity and feedback trading, including the role of volatility, on European stock markets. The aim and motivation of this paper is twofold. First, European markets have recently experienced the twin crises of the recession arising from the finance induced credit crunch and then the subsequent sovereign debt crisis. Thus, it seems timely to reconsider the nature of the relation between stock returns and illiquidity. Second, an examination of the interaction between illiquidity and feedback trading has not previously been examined. In particular, we argue that feedback trading may be more apparent when liquidity is low (illiquidity is high). That is, if trading is thin, it may encourage investors to trade with the current direction of the market. In contrast, when the market is highly liquid, investors may feel more confident in trading according to their own beliefs rather than following the market. Therefore, we establish as our key hypothesis that feedback trading will be positively related to illiquidity (or negatively related to liquidity).

A link between illiquidity and stock returns has been established by, among others, Amihud and Mendelson (1986), Acharya and Pedersen (2005), Amihud, (2002) and Pastor and Stambaugh (2003). This work suggests that illiquidity is a source of risk that should be priced in stock returns. Thus, a positive (negative) shock to illiquidity (liquidity), which increases risk, would lead to fall in current stock prices and an increase in expected future returns to compensate for the increase in risk. Subsequent empirical evidence supports this contention. This includes, for example, Amihud et al (2013), Amihud et al (2015) and Chiang and Zheng (2015), while De Jong and Driessen (2012) argue this relation is also present in the pricing of corporate bonds. Further, several authors report commonality in liquidity effects across international markets (e.g., Karolyi et al, 2012; Lee 2011). Notwithstanding this, some authors suggest that the stock return and illiquidity relation may not be constant 
across all firms. For example, Watanabe and Watanabe (2008) report that illiquidity is only priced in times of high market turnover, while Martinez et al (2005) report a negative relation between illiquidity and stock returns in the Spanish market. Finally, Mazouz et al (2010) report that illiquidity is not priced in stock trading in London. Therefore, it seems appropriate to re-assess the evidence on illiquidity and stock returns.

The recent feedback literature largely began with the work of Sentana and Wadhwani (1992), who examine how the presence of feedback traders impact return correlations and the role that volatility plays. They argue that feedback trading (positive autocorrelation in returns) will increase with volatility as smart (non-feedback) traders require a higher risk premium and thus the price deviates from equilibrium. Evidence for positive feedback is provided by Koutmos (1997), who reports that positive feedback is more likely in periods of high volatility and market declines. Regarding other markets, Laopodis (2005) reports similar feedback effects in US Dollar foreign exchange markets, while Anoniou et al (2005) do likewise for index futures and Chau et al (2011) for exchange traded funds (ETFs).

Concurrent within the literature is the study of the relation between volatility and illiquidity. Notably, Stoll (1978, 2000), Amihud and Mendelson (1989) and Bao and Pan (2013) report a positive relation between return volatility and illiquidity. It is argued that this arises because higher volatility increases the risks and costs associated with inventory holdings for those acting as market makers, and of adverse selection. Of particular note, Amiram et al (2016) argue that this positive relation is driven by the jump component of volatility, which itself arises from information shocks and thus cannot be hedged. This will heighten the costs associated with the volatility increase and reduce liquidity.

Therefore, this paper reconsiders the behaviour of stock returns with illiquidity, feedback trading and volatility, as well as the interaction between these variables. We examine the behaviour of several European markets, using panel regression methods, over the 
period from the beginning of 2006 to the end of 2017. This is a particularly interesting period as these markets have been buffeted by shocks arising from the financial crisis as well as the sovereign debt crisis. Thus, it is a period that has witnessed negative shocks to liquidity as well as heightened volatility and so serves as an ideal period in which to examine the dynamic links between these series when the market is under stress. This will contribute to our understanding of asset pricing and how investors react under different market conditions, the results of which will be informative for traders and market regulators.

\section{Data, Empirical Methodology and Hypotheses Development.}

Data is obtained for the European markets of, Denmark, France, Germany, Italy, Netherlands, Norway, Portugal, Spain, Switzerland and the UK. The data is daily over the time period from $1 / 1 / 2006$ to $31 / 12 / 2017$ and we obtain the total market index and volume from DataStream. For the volatility data, we use realised volatility that is obtained from 5-minute intra-day data series (see Andersen and Bollerslev, 1998). This data is obtained from the Oxford-Man Institute of Quantitative Finance realised volatility library.

To examine the relation between stock returns and illiquidity, we follow the approach introduced by Amihud (2002) to model illiquidity. This approach is widely used in the context of liquidity modelling, with the Aimihud illiquidity ratio, $A_{t}$, given by:

$$
A_{t}=\left|r_{t}\right| / V O L_{t}
$$

where $\left|r_{t}\right|$ represents the absolute return on the stock at time $t$ and $V O L_{t}$ represents the corresponding cash volume. ${ }^{1}$ This measure implies that a higher level of volume is associated with higher liquidity (lower illiquidity) and represents the absolute return (price change) per

\footnotetext{
${ }^{1}$ The stock return is calculated as the first-difference of the $\log$ price.
} 
monetary unit of trading volume. Thus, it is intended to capture price impact.

We can then examine the impact of illiquidity on stock returns. Notably, we can consider the notion that the impact of illiquidity on contemporaneous returns is negative, while the lagged effect is positive. This means that a negative shock to liquidity reduces the current price and increases the expected future return as the illiquidity shock raises risk. Thus, we estimate the following panel regression:

$$
r_{i t}=\alpha+\beta_{1} A_{i t}+\beta_{2} A_{i t-1}+\rho r_{i t-1}+\gamma_{i}+\varepsilon_{i t}
$$

Where $r_{i t}$ is the stock return for market $i$ at time $t, A_{i t}$ is defined in equation (1), $\gamma_{i}$ is the crosssection term and $\varepsilon_{i t}$ is the accompanying white noise error term. As noted, we expect $\beta_{1}$ to be negative and $\beta_{2}$ to be positive. The lagged return captures any serial correlation in the returns series. We also expand this regression by considering whether the strength of the illiquidity relation depends on the value of returns. Thus, we incorporate an interaction term between returns and illiquidity, as such:

$$
r_{i t}=\alpha+\beta_{1} A_{i t}+\beta_{2} A_{i t-1}+\beta_{3} A_{i t} r_{i t-1}+\rho r_{i t-1}+\gamma_{i}+\varepsilon_{i t}
$$

This will allow us to examine whether the relation between current stock returns and illiquidity varies for a given level of lagged stock returns. For example, when lagged stock returns are higher, we are considering whether a shock to current illiquidity has a greater or lesser impact on current stock returns.

From recent work (e.g., Chiang and Zheng, 2015), we also consider unexpected illiquidity. The argument here is that only unexpected changes in illiquidity moves prices, with the information content of expected illiquidity changes already reflected in stock value. 
Therefore, we estimate the following regression for each market:

$$
A_{t}=\alpha+\gamma A_{t-1}+\eta_{t}
$$

Where we use the residual term $\eta$ as our measure of unexpected illiquidity and repeat the regression from equation (2) but replace the $A_{i t}$ term with $\eta_{i t}$.

To capture the potential for feedback trading we follow the method of Sentana and Wadhwani (1992), which in turn is based upon the work of Shiller (1984) and Cutler et al (1990). Several papers report supportive evidence of feedback trading using this approach (e.g., Koutmos, 1997; Koutmos and Saidi, 2001; Laopodis, 2005; Salm and Schuppli, 2010; Charteris et al, 2014). Thus, we present here the regression model designed to test the presence of feedback traders:

$$
r_{i t}=\alpha+\theta V_{i t}+\varphi_{0} r_{i t-1}+\varphi_{1} V_{i t} r_{i t-1}+\varphi_{2}\left|r_{i t-1}\right|+\gamma_{i}+\varepsilon_{i t}
$$

Where $\mathrm{V}$ is volatility, again $r_{i t}$ is stock returns and $|$.$| refers to the absolute value. The$ presence of feedback depends on the parameter $\varphi_{1}$, where a negative value indicates the presence of positive feedback traders, while a positive $\varphi_{2}$ indicates that negative returns increase the effect of feedback.

The key aim of the paper is to examine the interaction between illiquidity and positive feedback trading. We consider this in two ways. First, we include interaction effects between illiquidity and feedback in the following regression:

$$
r_{i t}=\alpha+\theta V_{i t}+\varphi_{0} r_{i t-1}+\delta_{1} A_{i t}+\varphi_{1} V_{i t} r_{i t-1}+\delta_{2} A_{i t} r_{i t-1}+\delta_{3} A_{i t} V_{i t} r_{i t-1}+\varphi_{2}\left|r_{i t-1}\right|+\gamma_{i}+\varepsilon_{i t}
$$


In particular, we are interested in the interaction term between the Amihud illiquidity term and the positive feedback terms, hence the $\delta_{3}$ coefficient. Notably, we are interested in whether for a given level of illiquidity, feedback trading is stronger.

Second, we consider an alternative approach to examine the relation between illiquidity and feedback. For each market we re-estimate equation (5) using a one-year rolling fixed window and obtain the time-varying feedback parameter, $\varphi_{1}$. As noted above, a value of this parameter of less than zero indicates positive feedback behaviour. Therefore, we construct an indicator variable that equals one when $\varphi_{1}$ is negative and zero otherwise and estimate the following regression:

$$
I_{\mathrm{it}}\left(\varphi_{i 1}\right)=\alpha+\phi A_{i t}+\theta r_{i t}+\gamma_{i}+\xi_{t}
$$

Where $I_{t}$ refers to the indicator function as discussed above, while $A_{t}$ and $r_{t}$ are the Amihud illiquidity measure, equation (1), and stock returns respectively. A positive value on $\phi$ would suggest that an increase in illiquidity is associated with an increase in feedback trading.

In this section, we consider the possible range of interactions between stock returns, illiquidity and positive feedback trading. This begins by examining the separate and then joint influences of illiquidity and positive feedback effects on stock returns before considering the relation between illiquidity and feedback. Thus, to summarise the full set of hypotheses to be tested in the subsequent sections, Table 1 indicates the appropriate equation, expected coefficient sign and rationale for that expected coefficient sign.

\section{Stock Returns and Illiquidity.}

We begin our analysis by considering the relation between stock returns and illiquidity over the full sample period. The results for this exercise are reported in Table 2. We report the 
results for different assumptions regarding the cross-sectional behaviour of the markets, including a common constant, fixed and random effects. Across all the three different panel methods, we can observe a negative and statistically coefficient between contemporaneous stock returns and the Amihud illiquidity ratio. This means that higher illiquidity is associated with a low stock return within the same time period. With regard to the lagged Amihud ratio, we see the opposite picture emerge, where the coefficient is positive and statistically insignificant across the three different estimation methods. The statistical insignificance thus runs counter to the common perception that a change in liquidity leads to a change in expected future returns due to liquidity acting as a risk factor. This perhaps indicates that since the initial reporting of the lagged liquidity effect markets have become quicker at incorporating such information into prices. As noted in the Introduction, the finding that illiquidity is not priced is not new (e.g., Mazouz et al, 2010), while the recent work of Harris and Amato (2018) and Drienko et al (2018) equally cast doubt on the predictive ability of the Amihud ratio. In terms of the appropriate model specification as given by the panel test, we can see that the common constant pooled model is adequate. ${ }^{2}$

We investigate the relation between returns and illiquidity is two further ways. First, Table 3 presents the results in which the contemporaneous Amihud ratio term enters the equation both separately and as an interaction term with lagged returns. This allows us to consider whether the relation strengthens for a given level of returns. We focus on the contemporaneous effect only in this regression as the lagged interaction effect is insignificant across the markets. These results support the general view that higher lagged returns are associated with a stronger negative impact of illiquidity on current returns. Notably, the coefficient sign is negative and significant at the 5\% level across the three estimation methods. Again, according to the panel tests, the common constant model is sufficient.

\footnotetext{
${ }^{2}$ The two tests are, first, for the null of a common constant against fixed effects (reported in the Fixed Effects row) and second, for the null of random effects against fixed effects (reported in the Random Effects row).
} 
Second, we consider the impact of the illiquidity surprise. The results are presented in Table 4 and show consistency across the estimation methods and with the results in Table 2 . Of particular note, the relation between contemporaneous stock returns and unexpected illiquidity is negative and significant at the 5\% significance level. Thus, an unexpected increase in illiquidity leads to a fall in the current price. With regard to lagged unexpected illiquidity, while this is also negative, it is statistically insignificant. Arguably, the effects of an unexpected change one period ago should no longer impact current returns as the information should be absorbed by prices. In conjunction with the results in Table 2, this does suggest that illiquidity has no significant relation with future (expected) returns.

\section{Stock Returns and Feedback Trading.}

Table 5 presents the results of the standard feedback trading model of Sentana and Wadhwani (1992). Of particular interest in these results is the sign and significance of the parameter $\phi_{1}$, which determines the nature and existence of any feedback trading behaviour. Evident from the table is that this coefficient is negative and statistically significant for our European markets across all the estimation methods. This result is consistent with the papers cited in the Introduction and the more recent work of, for example, Hou and Li (2014). Of further interest is the behaviour of the parameter $\phi_{2}$, which indicates asymmetry in the response of returns to feedback behaviour. While this parameter indicates a negative relation, it is statistically insignificant.

These results thus support the view that, in general, the European markets considered in this analysis can be characterised by positive feedback trading behaviour. Furthermore, the results here do not suggest any asymmetry in response to positive or negative returns. 


\section{Feedback Trading and Illiquidity.}

We now turn to those results that consider whether there exists a relation between feedback trading and illiquidity. In order to examine this, we consider two approaches. First, we conduct a regression in which we include both the illiquidity and feedback variables together, including an interaction term. Second, we define a dummy variable which equals one when the feedback coefficient, $\phi_{1}$ from equation (5) is negative (i.e., positive feedback) and zero otherwise based on a one-year rolling window. This dummy variable is then regressed on the Amihud illiquidity measure and lagged returns using a probit approach.

The results from the first approach are reported in Table 6. Our underlying view is that a higher degree of illiquidity will lead to greater feedback trading as the impact of trades will be more apparent, resulting in feedback traders receiving clear signals in how to trade. Our results are supportive of this view as the coefficient on the interaction term between feedback and illiquidity is negative and statistically significant across the different panel estimation methods. This mean that for an increasing level of illiquidity, there is greater evidence of positive feedback behaviour.

The results of the second approach are reported in Table 7 . These results provide a more direct indication of the relation between illiquidity and feedback. Here, we can see that across the European markets there is a positive relation between the Amihud measure and the feedback dummy and that this is statistically significant. This suggests that an increase in illiquidity is associated with an increase in positive feedback. Thus, the results in both Tables 6 and 7 confirm the view that a lower level of liquidity is associated with a higher degree of positive feedback trading. Of interest, the results in Table 7 are the only reported regression specification that indicates preference for the fixed effects specification in the panel model as opposed to a common constant. 


\section{Summary and Conclusion.}

This paper has sought to re-examine the nature of the relations between stock returns, illiquidity and feedback trading for a series of European markets through the period of the financial and sovereign debt crises. Existing empirical evidence has highlighted the presence of feedback trading within stock markets and the belief that illiquidity is a priced risk that leads to an increase in expected future returns. We seek to establish whether these results continue to hold during crisis periods. Moreover, in contrast to the existing literature, we also consider the interaction between illiquidity and feedback trading.

We calculate illiquidity using the Amihud ratio, which has become a standard approach within the literature, and use this to model the relation with stock returns. In addition, we also estimate an AR(1) equation for the Amihud ratio and use the residual term to examine the impact of unexpected illiquidity on stock returns. Subsequent to this, we turn our attention to evidence of feedback trading within stock returns before examining the interactions effects between illiquidity and feedback trading both among themselves and with stock returns. In estimating the statistical relations we adopt a panel regression approach.

The key results in the paper can be summarised as follows. Illiquidity has a negative impact upon contemporaneous stock returns, thus, a negative shock to liquidity results in a fall in the current price. Such a result is consistent with the existing literature. Lagged illiquidity, however, has no significant impact on returns. This, contrasts with the view that illiquidity is a priced risk, although the prevailing literature is mixed on this point. Unexpected illiquidity has the same impact on contemporaneous stock returns as overall illiquidity. The results show the presence of positive feedback trading, although, there is no accompanying evidence of asymmetry between positive and negative returns. A final set of results provides evidence that a rise in illiquidity is associated with an increase in feedback trading. This supports the view that when price changes are more observable under thin 
markets then feedback trading increases.

In conclusion, the results reported here suggest that during the crisis periods that recently afflicted European markets, the lower levels of liquidity observed in the markets led to an increase in feedback trading. The negative liquidity shocks also lead to a fall in stock prices, which are then exacerbated by feedback trading. It would be of interest in future research to examine these relations across markets characterised by different liquidity levels, notably emerging and frontier markets and over different crisis and non-crisis periods. 


\section{References}

Acharya, V and Pedersen, L (2005), 'Asset pricing with liquidity risk', Journal of Financial Economics, 77, 375-410.

Amihud, Y (2002), 'Illiquidity and stock returns: Cross-section and time-series effects', Journal of Financial Markets, 5, 31-56.

Amihud, Y, Hameed, A, Kang, W and Zhang, H (2015), 'The illiquidity premium: International evidence', Journal of Financial Economics, 117, 350-368.

Amihud, Y and Mendelson, H (1986), 'Asset pricing and the bid-ask spread', Journal of Financial Economics, 17, 223-249.

Amihud, Y and Mendelson, H (1989), 'The effects of beta, bid-ask spread and residual risk, and size on stock returns', Journal of Finance, 44, 479-486.

Amihud, Y, Mendelson, H and Pedersen, L (2013), Market Liquidity: Asset Pricing, Risk, and Crises. Cambridge University Press, Cambridge: UK.

Amiram, D, Cserna, B and Levy, A (2016), 'Volatility, liquidity and liquidity risk', Working Paper, Columbia Business School, https://www8.gsb.columbia.edu/facultyresearch/sites/faculty-research/files/ACLBurton.pdf

Antoniou, A, Koutmos, G, and Pericli, A (2005), 'Index futures and positive feedback trading: Evidence from major stock exchanges', Journal of Empirical Finance, 12, 219-238.

Bao, J and Pan, J (2013), 'Bond illiquidity and excess volatility', Review of Financial Studies, 26, 3068-3103.

Charteris A, Chau F, Gavriilidis K and Kallinterakis V (2014), 'Premiums, discounts and feedback trading: Evidence from emerging markets' ETFs', International Review of Financial Analysis, 35, 80-89.

Chau, F, Kuo, J and Shi, Y (2015), 'Arbitrage opportunities and feedback trading in emissions and energy markets', Journal of International Financial Markets, Institutions and Money, 36, 130-147.

Chiang, T and Zheng, D (2015), 'Liquidity and stock returns: Evidence from international markets', Global Finance Journal, 27, 73-97.

Cutler, D, Poterba, J and Summers, L (1990), 'Speculative dynamics and the role of feedback traders', American Economic Review, 80, 63-68.

De Jong, F and Driessen, J (2012), 'Liquidity risk premia in corporate bond markets', Quarterly Journal of Finance, 2 (2).

Drienko, J, Smith, T and von Reibnitz, A (2018), 'A Review of the Return-Illiquidity Relationship', Critical Finance Review, (forthcoming), http://cfr.ivowelch.info/readers/2018/drienko-smith-reibnitz-2017.pdf. 
Harris, L and Amato, A (2018), 'Illiquidity and stock returns: Cross-section and time-series effects: A replication', USC Marshall, School of Business Working Paper, http://cfr.ivowelch.info/readers/2018/harris-amato-2018.pdf.

Hou, Y and Li, S (2014), 'The impact of the CSI 300 stock index futures: Positive feedback trading and autocorrelation of stock returns', International Review of Economics and Finance, 33, 319-337.

Karolyi, G, Lee, K and Van Dijk, M (2012), 'Understanding commonality in liquidity around the world', Journal of Financial Economics, 105, 82-112.

Koutmos, G (1997), 'Feedback trading and the autocorrelation pattern of stock returns: further empirical evidence', Journal of Empirical Finance, 16, 625-636.

Koutmos, G and Saidi, R (2001), 'Positive feedback trading in emerging capital markets', Applied Financial Economics, 11, 291-297.

Laopodis, N (2005), 'Feedback trading and autocorrelation interactions in the foreign exchange market: Further evidence’, Economic Modelling, 22, 811-827.

Lee, K-H (2011), 'The world price of liquidity risk', Journal of Financial Economics, 99, 136-161.

Martinez, M, Nieto, B, Rubio, G and Tapia, M (2005), 'Asset pricing and systematic liquidity risk: An empirical investigation of the Spanish stock market', International Review of Economics and Finance, 14, 81-103.

Mazouz, K, Alrabadi, W, Freeman M and Yin, S (2010), 'Systematic liquidity risk and asset pricing: Evidence from London Stock Exchange', International Journal of Banking, Accounting and Finance, 2, 387-403.

Pastor, L and Stambaugh, R (2003), 'Liquidity risk and expected stock returns', Journal of Political Economy, 111, 642-685.

Salm, C, and Schuppli, M (2010), 'Positive feedback trading in stock index futures: International evidence', International Review of Financial Analysis 19, 313-322.

Sentana, E and Wadhwani, S (1992), 'Feedback traders and stock return autocorrelations: Evidence from a century of daily data', Economic Journal, 102, 4, 15-425.

Shiller, R (1984), 'Stock prices and social dynamics', Brookings Papers on Economic Activity, 2, 457-498.

Stoll, H (1978), 'The supply of dealer services in securities markets', Journal of Finance, 33, 1133-1151.

Stoll, H (2000), 'Friction', Journal of Finance, 55, 1479-1514. 
Watanabe, A and Watanabe, M (2008), 'Time-varying liquidity risk and the cross section of stock returns', Review of Financial Studies, 21, 2449-2486. 
Table 1. Testable Hypotheses

\begin{tabular}{|c|c|c|}
\hline Equation(s) & Coefficient Sign(s) & Rationale \\
\hline $\mathrm{Eq}(2)$ & $\beta_{1}<0 ; \beta_{2}>0$ & $\begin{array}{l}\text { Illiquidity is a priced risk factor. An increase } \\
\text { in illiquidity will reduce the current prices and } \\
\text { increase future expected returns }\end{array}$ \\
\hline Eqs (2) and (4) & $\beta_{1}<0 ; \beta_{2}>0$ & $\begin{array}{l}\text { Unexpected illiquidity from equation (4) is the } \\
\text { priced factor in equation ( } 2 \text { ) }\end{array}$ \\
\hline $\mathrm{Eq}(6)$ & & $\begin{array}{l}\text { An increase in illiquidity leads to greater } \\
\text { feedback trading }\end{array}$ \\
\hline $\mathrm{Eq}(7)$ & $\phi>0$ & $\begin{array}{l}\text { An increase in illiquidity leads to greater } \\
\text { feedback trading }\end{array}$ \\
\hline \multicolumn{3}{|c|}{$\begin{array}{l}\text { Notes: Equations: } \\
\qquad r_{t}=\alpha+\beta_{1} A_{t}+\beta_{2} A_{t-1}+\rho r_{t-1}+\varepsilon_{t} \\
\text { (2) } r_{t}=\alpha+\beta_{1} A_{t}+\beta_{2} A_{t-1}+\beta_{3} A_{t} r_{t-1}+\rho r_{t-1}+\varepsilon_{t} \\
\text { (3) } A_{t}=\alpha+\gamma A_{t-1}+\eta_{t} \\
\text { (4) } r_{t}=\alpha+\theta V_{t}+\varphi_{0} r_{t-1}+\varphi_{1} V_{t} r_{t-1}+\varphi_{2}\left|r_{t-1}\right|+\varepsilon_{t} \\
\text { (5) } \quad V_{t}=\alpha+\theta V_{t}+\varphi_{t-1}+\delta_{1} A_{t}+\varphi_{1} V_{t} r_{t-1}+\delta_{2} A_{t} t_{t-1}+\delta_{3} A_{t} V_{t} r_{t-1}+\varphi_{2}\left|r_{t-1}\right|+\varepsilon_{t} \\
\text { (6) } \quad r_{t}\left(\varphi_{1}\right)=\alpha+\phi A_{t}+\theta r_{t}+\xi_{t} \\
\text { (7) } \\
\text { Where } r_{t} \text { is the stock return, } A_{t} \text { is the Amihud illiquidity ratio, } \mathrm{V} \text { is volatility, }|.| \text { refers to the absolute value, } I_{t} \text { is an indicator function } \\
\text { depending on the value of } \varphi_{1} \text { and } \varepsilon_{t} \text { and } \eta_{t} \text { are white noise error terms. All these models are estimated in a panel regression, however, we drop the } \\
\text { cross-section specific terms for ease of presentation. }\end{array}$} \\
\hline
\end{tabular}


Table 2. Stock Return - Amihud Illiquidity Regression

\begin{tabular}{|l|l|l|l|l|}
\hline Panel Method & Amihud & Lagged Amihud & Lagged Return & Panel Test \\
\hline Pooled & -0.015 & 0.015 & 0.017 & - \\
& $(-3.31)$ & $(0.32)$ & $(2.92)$ & \\
\hline Fixed Effects & -0.017 & 0.022 & 0.017 & 0.99 \\
& $(-3.92)$ & $(0.97)$ & $(2.91)$ & \\
\hline Random Effects & -0.016 & 0.010 & 0.017 & \\
& $(-3.54)$ & $(0.31)$ & $(2.94)$ & \\
\hline
\end{tabular}

Notes: Entries are coefficient values and $t$-statistics from equation (2):

$r_{i t}=\alpha+\beta_{1} A_{i t}+\beta_{2} A_{i t-1}+\rho r_{i t-1}+\gamma_{i}+\varepsilon_{i t}$

Where $r_{i t}$ is the stock return for market $\mathrm{i}$ at time $\mathrm{t}, A_{i t}$ is defined in equation (1), $\gamma_{\mathrm{i}}$ is the cross-section term and $\varepsilon_{i t}$ is the accompanying white noise error term. 
Table 3. Stock Return - Amihud Illiquidity Regression with Interaction Term

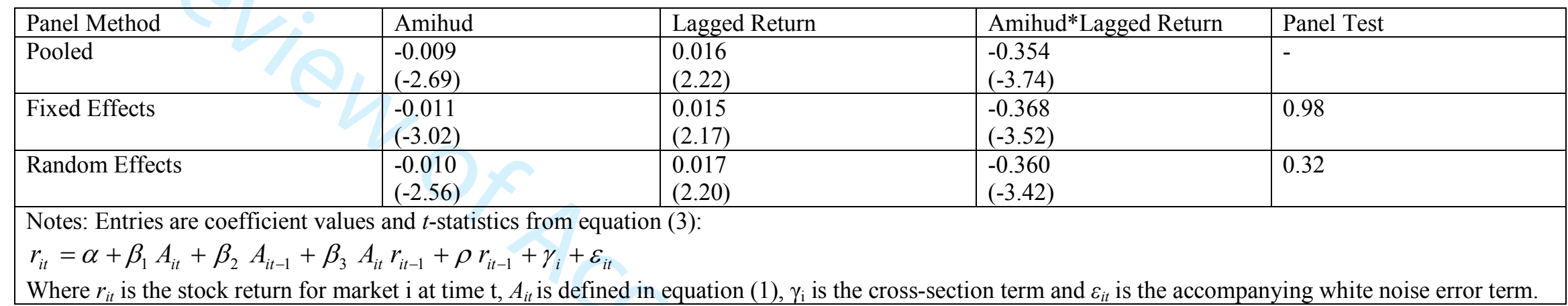


Table 4. Stock Return - Unexpected Amihud Illiquidity Regression

\begin{tabular}{|c|c|c|c|c|}
\hline Panel Method & Unexpected Amihud & Lagged Unexpected Amihud & Lagged Return & \begin{tabular}{|l} 
Panel Test \\
\end{tabular} \\
\hline 8 & \begin{tabular}{|l|}
-0.018 \\
$(-3.25)$ \\
\end{tabular} & $\begin{array}{l}-0.012 \\
(-0.32)\end{array}$ & $\begin{array}{l}0.016 \\
(2.24)\end{array}$ & - \\
\hline Fixed Effects & $\begin{array}{l}-0.017 \\
(-3.23) \\
\end{array}$ & $\begin{array}{l}-0.011 \\
(-0.33)\end{array}$ & $\begin{array}{l}0.016 \\
(2.22)\end{array}$ & 0.99 \\
\hline Random Effects & $\begin{array}{l}-0.018 \\
(-3.26)\end{array}$ & $\begin{array}{l}-0.012 \\
(-0.32)\end{array}$ & $\begin{array}{l}0.016 \\
(2.22)\end{array}$ & 0.34 \\
\hline \multicolumn{5}{|c|}{$\begin{array}{l}\text { Notes: Entries are coefficient values and } t \text {-statistics from equation (2): } \\
r_{i t}=\alpha+\beta_{1} A_{i t}+\beta_{2} A_{i t-1}+\rho r_{i t-1}+\gamma_{i}+\varepsilon_{i t} \\
\text { but where the term } A_{t} \text { is replaced by the term } \eta_{t} \text { from equation (4): } \\
A_{t}=\alpha+\gamma A_{t-1}+\eta_{t}\end{array}$} \\
\hline
\end{tabular}


Table 5. Stock Return - Feedback Regression

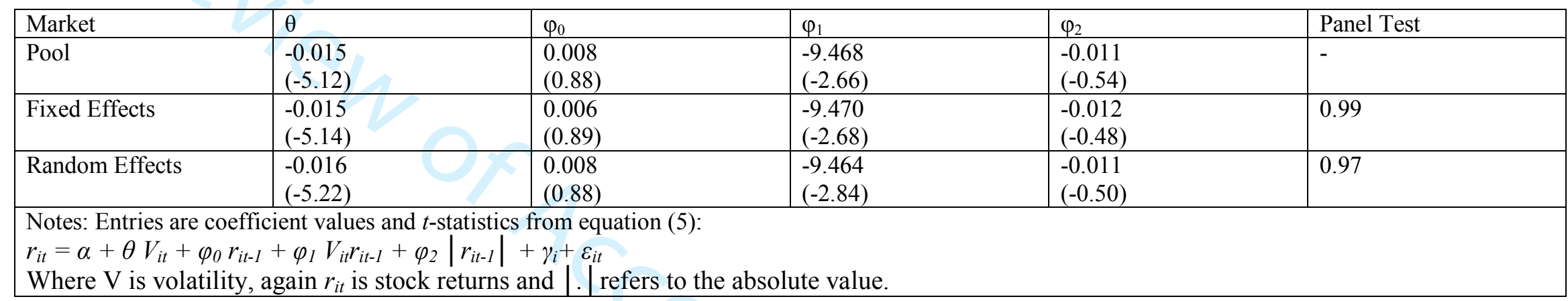


Table 6. Stock Return - Feedback Regression with Liquidity and Interaction Effects

\begin{tabular}{|l|l|l|l|l|l|l|l|l|}
\hline Market & $\theta$ & $\varphi_{0}$ & $\delta_{1}$ & $\varphi_{1}$ & $\delta_{2}$ & $\delta_{3}$ & $\varphi_{2}$ \\
\hline Pool & -2.780 & 0.017 & -0.032 & 17.258 & 0.042 & -135.220 & 0.016 \\
& $(-8.50)$ & $(2.33)$ & $(-2.66)$ & $(3.02)$ & $(0.64)$ & $(-2.74)$ & - \\
\hline Fixed Effects & -2.779 & 0.018 & -0.031 & 16.738 & 0.040 & -137.208 & 0.017 \\
& $(-8.48)$ & $(2.34)$ & $(-2.65)$ & $(2.98)$ & $(0.65)$ & $(-2.72)$ & $(2.00)$ \\
\hline Random Effects & -2.776 & 0.017 & -0.032 & 17.084 & 0.041 & -135.854 & 0.017 & 0.99 \\
& $(-8.52)$ & $(2.32)$ & $(-2.66)$ & $(2.95)$ & $(0.64)$ & $(-2.78)$ & $(2.00)$ & 0.99 \\
\hline
\end{tabular}

Notes: Entries are coefficient values and $t$-statistics from equation (6):

$r_{i t}=\alpha+\theta V_{i t}+\varphi_{0} r_{i t-1}+\delta_{1} A_{i t}+\varphi_{1} V_{i t} r_{i t-1}+\delta_{2} A_{i t} r_{i t-1}+\delta_{3} A_{i t} V_{i t} r_{i t-1}+\varphi_{2}\left|r_{i t-1}\right|+\gamma_{i}+\varepsilon_{i t}$

Where $r_{i t}$ is the stock return for market $\mathrm{i}$ at time $\mathrm{t}, A_{i t}$ is defined in equation (1), $V_{i t}$ is volatility, $\gamma_{\mathrm{i}}$ is the cross-section term and $\varepsilon_{i t}$ is the accompanying white noise error term. 
Table 7. Feedback - Amihud Probit Regression

\begin{tabular}{|l|l|l|l|}
\hline Panel Method & Returns & Amihud & Panel Test \\
\hline Pooled & 0.044 & 0.425 & - \\
& $(0.72)$ & $(2.08)$ & 0.00 \\
\hline Fixed Effects & 0.055 & 0.628 & $(5.68)$ \\
& $(1.22)$ & 0.6 .28 & 0.03 \\
\hline Random Effects & 0.054 & $(5.70)$ & \\
\hline Notes: Entries are coefficient values and $t$-statistics from equation (7): & \\
$I_{\text {it }}\left(\varphi_{i 1}\right)=\alpha+\phi A_{i t}+\theta r_{i t}+\gamma_{i}+\xi_{t}$ \\
Where $I_{i t}$ refers to an indicator function, while $A_{i t}$ and $r_{i t}$ are the Amihud illiquidity measure, equation (1), and stock returns respectively. \\
\hline
\end{tabular}

